\title{
LOS ARAUCANOS COMO PERSONAJES LITERARIOS
}

\author{
MIGUEL ÁNGEL AULADELL PÉREZ
}

Uno de los aspectos más inéditos en el análisis del hecho literario es el de la creación de personajes. Resulta un tanto oscuro y desconocido el funcionamiento de los resortes que conforman ese ser misterioso que es el personaje literario capaz de hacer remembrar al lector visiones de la realidad o de su imaginación. Las enormes posibilidades de acercamiento al estudio del personaje literario tienen un tratamiento singular cuando se aborda la traslación que la autoría individual o colectiva ha realizado desde la mitología, la leyenda o la Historia. Alrededor de ello queremos andar y escogemos el pueblo araucano y a su héroe Caupolicán, aquél que "anduvo» tan cargado y que ha quedado configurado como un indudable personaje de peso, tanto en la historia de todo un pueblo hasta hoy mismo, como en la rica tradición literaria a la que ha dado lugar. De este asunto ya me ocupé en otro artículo ${ }^{1}$ que entiendo como complementario y, por tanto, juzgo necesario retomar algunas consideraciones y ampliar algo de lo apuntado allí.

El soneto «Caupolicán» de Rubén Darío es, sin duda, uno de los textos literarios que más ha contribuido al conocimiento del héroe araucano en nuestra época. No obstante, me refería en ese artículo a la extensa relación de obras que acogían a Caupolicán como personaje destacado o incluso con carácter protagonista.

Hay que reiterar aquí el hecho de que la historia de Caupolicán nos ha llegado a partir de una relativamente extensa tradición textual detallada por el gran polígrafo José Toribio Medina ${ }^{2}$ y que tiene su comienzo en La Araucana de Alonso de Ercilla. De todas maneras, es de notar la existencia de otro tipo de documentos que también aluden al episodio antedicho y que, en general, dan cuenta, más o menos fidedignamente, de los hechos históricos que acontecieron en los primeros lustros de la conquista del territorio que actualmente ocupa Chile.

El episodio en cuestión se incardina en la sucesión de acontecimientos ocurridos hacia mediados del siglo XVI en plena expansión de las fundaciones españolas que dependientes del virreinato del Perú se llevaban a cabo por la región andina y que contó con enormes dificultades de sometimiento al llegar a la zona del río Bío Bío. Vivían tras esa verdadera línea fronteriza unos pueblos caracterizados por su gran fiereza. Fueron concretamente los mapuches los que atacaron inmediatamente a los invasores europeos y destruyeron la ciudad de Santiago, dando comienzo a las llamadas como guerras de Arauco. El territorio mapuche no ha llegado a ser integrado en Chile hasta el mismo siglo XX y no sin pasar por dolorosos capítulos que han hecho derramar mucha sangre. Afirma Patricio Lerzundi que «Los araucanos -que fue el nombre que les dieron los españoles a los mapuches por cuanto vivían en la región de Arauco-, eran los más belicosos de los grupos indígenas. Su lengua era el mapuche; desconocían [...] la escritura [...] y su cultura distaba mucho de la alcanzada por sus vecinos incas». Entre ellos «existía la poligamia, generalmente se reunían para tratar asuntos especiales, como la guerra, bajo el control del toqui, o jefe supremo, que era elegido por una asamblea de grupos de familia, o cahuines» ${ }^{3}$.
Miguel Ángel Auladell Pérez

Profesor Titular E.U. de literatura española de la Universidad de Alicante. Su actividad docente e investigadora se ha centrado principalmente en el siglo XVII y en la época Fin de Siglo. Ha formado parte de varios proyectos de investigación, tanto de financiación pública como privada. Ha participado en congresos nacionales e internacionales de su especialidad y ha publicado artículos sobre diversos escritores: Lucas Fernández, Antonio Liñán y Verdugo, Lope de Vega, Ruiz de Alarcón, Vicente García de la Huerta, José Zorri1la, Emilio Castelar, José Martí, Rubén Darío, Azorín, José Ortega y Gasset, Juan Gil-Albert, Migue Hernández, José Sanchis Sinisterra. Es autor de la monografía titulada La 'Guía y avisos de forasteros que vienen a la Corte' del Ldo. Antonio Liñán y Verdugo en su contexto literario y editor del Ensayo bio-bibliográfico de escritores de Alicante y su provincia de Manuel Rico García. Actualmente, dirige la edición digital de la obra de Lope de Vega en la Biblioteca Virtual Cervantes.

1 «De Caupolicán a Rubén Darío», en Carmen Alemany y Eva Valero (coords.), Recuperaciones del mundo precolombino y colonial. América sin nombre, 5-6 (dic. 2004), pp. 12-21.

2

Véase José Carlos Rovira, José Toribio Medina y su fundación literaria y bibliográfica del mundo colonial americano, Santiago de Chile, DIBAM/Centro de Investigaciones Diego Barros Arana, 2002

3

Patricio Lerzundi, Arauco en el teatro del Siglo de Oro, Valencia, Albatros Hispanófila, 1996 p. 10.
Los araucanos como personajes literarios

MIGUEL ÁNGEL AULADELL PÉREZ 


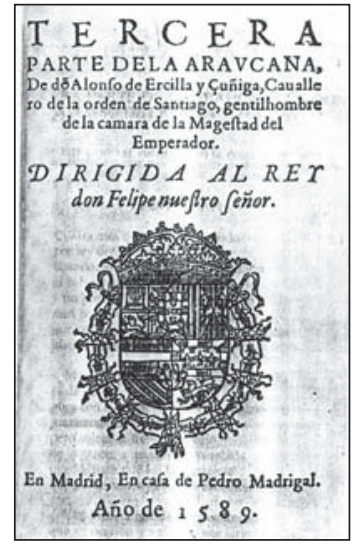

Portada de la Tercera Parte de La Araucana de Ercilla (1589).

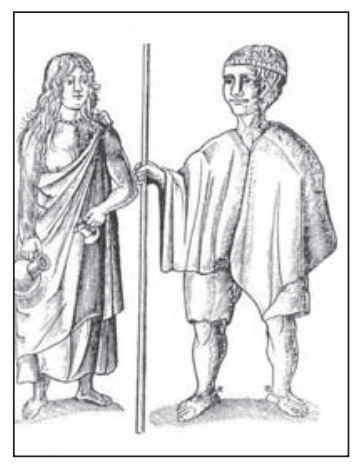

Araucanos (grabado).

4

Alonso de Ercilla, La Araucana, ed. Isaías Lerner, Madrid, Cátedra, 2002, p. 19

5

Claudio Cifuentes Aldunate, "Caupolicán: creación y recreaciones de un mito", Noter og kommentarer fra Romansk Institut, Odense Universitet, 53 (1982), p. 64.

6

Sobre los bautizos de caciques puede verse Tzvetan Todorov, La Conquista de América. El problema del otro, México, Siglo $X X I, 2001^{12}\left(1^{\underline{a}}\right.$ ed. en francés: 1982), p. 183.
Con tales características los aguerridos araucanos serían, tal vez, como ningunos otros aborígenes del Nuevo Mundo, los que infligirían mayores bajas en las fuerzas de conquista y acabarían con grandes símbolos de los invasores. La tremenda rivalidad de que hicieron gala los contendientes aseguró una pléyade de testimonios literarios que por uno $\mathrm{u}$ otro motivo quisieron hacerse eco de aquel acontecer histórico. Nombres como Lautaro, Caupolicán, Galbarino, Colo Colo -por los mapuches-; y como Pedro de Valdivia, Francisco de Villagra, García Hurtado de Mendoza o el mismo Alonso de Ercilla -por los españoles-, configuran un elenco de personajes que van a ser leídos y reconocidos en el sentido categórico que atribuye Roland Barthes a ese tipo de tradición literaria que en cada reescritura va transformando el motivo, el tema, el mito. En resumen, un conjunto de dramatis personae que son uña y carne de la re-creación a lo largo del tiempo y que, sobre todo, tuvo durante el siglo XVII su mejor traslación precisamente al género teatral. También algunos lugares van a conformar la geografía de toda esa estela intertextual: Santiago, La Serena, Tucapel, Pilmaiquén, Cañete, el Fuerte Purén. Por consiguiente, es preciso resaltar una vez más cómo la creación artística, en esta ocasión la literatura, contribuye a edificar culturalmente un nuevo mundo, pero simultáneamente éste abastece de extraordinarios e insólitos recursos el canon retórico del humanismo y posteriormente de otras estéticas que van emergiendo en Europa.

Fue Alonso de Ercilla el que, a través de La Araucana, permitió con su grandioso poema épico apreciar hasta qué punto quedaban marcadas muchas de las posibilidades de recreación de los acontecimientos vividos. El motivo -como venimos comentando- de mayor fortuna entre todos los devenidos de los episodios recreados es, sin duda, el que tiene como personaje central a Caupolicán. Isaías Lerner afirma que:

Los elementos de la trama que componen la narración de la historia no son materia comprobable, pero las referencias geográficas y culturales de Chile y sus habitantes, los hechos bélicos, fueron tenidos por auténticos desde muy temprano y durante mucho tiempo, puesto que las fuentes del propio Ercilla para los hechos en los que no participó personalmente no nos son completamente conocidos ${ }^{4}$.

Los araucanos como personajes literarios

MIGUEL ÁNGEL AULADELL PÉREZ en cinco las etapas de evolución del personaje de Caupolicán y sus correspondientes representaciones ${ }^{5} 1^{\mathrm{a}}$ ) Unidad dual. Fuerza corporal e inteligencia al servicio de su pueblo. Vencedor, famoso y en equidad de roles con Carlos V. $2^{a}$ ) desintegración de su imagen. Unidad dual de fuerza e inteligencia al servicio de sí mismo. Pérdidas bélicas, pérdida de prestigio y de fama. $3^{a}$ ) Restablecimiento parcial de su imagen a través de la elocuencia y sagacidad. $\left.4^{a}\right)$ Desintegración total de su imagen en la persecución y apresamiento. $5^{a}$ ) Recuperación de su integridad a través del bautizo ${ }^{6}$ y la muerte. Valiente, temido y digno, es ejecutado con el atributo cristiano del que carecía.

Es tremendamente significativo que toda re-escritura de la historia de Caupolicán recoge una, dos o más de estas etapas. Eso sí, en algunos casos se incluyen motivos nuevos que van enriqueciendo el tema; en otros son el tono o el recipiente genérico los que aportan una peculiaridad sobresaliente y genuina a determinada obra. Rubén Darío llevó a cabo, según defendí en su momento, la síntesis de una de esas etapas de desarrollo del personaje plasmado por Ercilla, concretamente en el Canto II de la primera parte de La Araucana (1569).

Todos los géneros se han rendido ante Caupolicán. La importancia intrínseca del personaje y del hombre ha motivado la atención al mismo en la correspondencia de sus rivales, los conquistadores españoles, y así tenemos como uno de los primeros testimonios relativos al formidable guerrero las cartas de Pedro de Valdivia. Enseguida, han de señalarse las crónicas que aparte de su carácter documental encierran, en muchos de los casos, valiosos ejercicios estilísticos que adquieren una categoría literaria. Se trata de: Crónica y relación copiosa y verdadera de los reinos de Chile, de Jerónimo de Vivar; Historia de Chile desde su descubrimiento hasta el año 1575, de Alonso de Góngora Marmolejo; Crónica del reino de Chile, de Pedro Mariño de Lobera y Bartolomé de Escobar; Hechos de don García Hurtado de Mendoza, cuarto marqués de Cañete, de Cristóbal Suárez de Figueroa. Entre los textos de carácter literario destacan dos obras: la ya mencionada de Alonso de Ercilla -La Araucana (1569)-, y Arauco domado (1596), de Pedro de Oña; estas obras siguen el patrón del género épico en práctica durante el Renacimiento y están directamente relacionadas por cuanto la segunda es pieza de encargo para tratar de corregir parte de los extremos que, según algunos, contenía el poema de Ercilla y también por razón de 
que Aranco domado comienza su andadura a partir de un momento recogido en la primera de las tres partes de La Araucana. Ya en el siglo XVII, el tema de Caupolicán y todos los motivos que lleva anejos se constituye como elección predilecta para el género dramático. Y así tenemos: La bellígera española (1616) de Ricardo del Turia; Algunas hazañas de las muchas de don García Hurtado de Mendoza, Marqués de Cañete (1622) de Luis de Belmonte Bermúdez y colaboradores; Aranco domado (Parte XX, 1625) de Lope de Vega; El gobernador prudente (1663), de Gaspar de Ávila; Los españoles en Chile (1665) de Francisco González de Bustos; y el auto sacramental La Araucana (principios del s. XVII), también de Lope de Vega.

Otros textos literarios inspirados directa o indirectamente por el tema de Arauco son los siguientes: Quince romances anónimos basados en La Araucana (1589-1593); Cuarta y Quinta parte de La Arancana, poema épico de Diego de Santisteban de Osorio (1598); Historia Tragicómica de don Enrique de Castro, novela de caballerías de Francisco de Loubayssin de la Marca (París, 1617); Las guerras de Chile, poema épico de Juan de Mendoza Monteagudo; Purén indómito, crónica rimada de Hernando Álvarez de Toledo; El cautiverio feliz, memorias en verso de Francisco Núñez de Pineda y Bascuñán; Restauración de la Imperial y conversión de almas infieles, novela de Fray Juan de Barrenechea y Alvis (ca. 1693).

Una vez que, tras el paréntesis ilustrado y romántico, es recuperado el gusto por la mitología, la estética modernista posibilita que nuestro tema vuelva a re-escribirse. Y he aquí otra muestra recreadora del mito distinta de la de Darío: el «Caupolicán» de José Santos Chocano, primero de los sonetos incluidos en el «Tríptico heroico» de Alma América (1906). Asimismo, es imposible dejar de mencionar alguna muestra posterior a Darío como mejor modo de corroborar el éxito del motivo y la atención que le han dispensado creadores tan diversos. El caso más excelso es, sin duda, el de Pablo Neruda. Entre sus muchos escritos de preocupación directa por el mundo indígena, destacan dos poemas -«Toqui Caupolicán» (V) y «El empalado» (VII)- pertenecientes a la serie titulada «Los Libertadores», incluida en el Canto general (1950). Además de todo lo relacionado, debemos aludir también a la importante presencia del tema en otros ámbitos artísticos como la plástica o la música.
En nuestros días, todavía Caupolicán sigue re-escribiéndose. Cuando el problema mapuche está aún lejos de quedar resuelto, pueden visitarse a través de internet varios lugares en donde el guerrero sigue irguiendo su «alta frente» porque siguen escribiéndose poemas que tienen como referente ese imaginario cultural que en la época de Fin de Siglo contribuyó a universalizar el poeta de Nicaragua y de América.

La cuestión que se plantea aquí es la de acercarse a cómo toda esta epopeya y mitología que encierra un importante componente histórico ha gozado de una adaptación literaria tan exitosa. La razón fundamental reside en la conversión del personaje histórico en personaje literario. Además, ese personaje literario representa el tipo de protagonista trágico de raigambre aristotélica. La traslación al Viejo Mundo de las hazañas emprendidas por los héroes del Nuevo es casi obra de la geometría. Las palabras de Robert Abirache cuando trata de caracterizar la identidad y la función del personaje en su libro fundamental La crisis del personaje en el teatro moderno, resultan que ni pintiparadas para lo que nos estamos refiriendo:

En la tragedia, el nombre del personaje se toma prestado a la historia o a la leyenda: casi siempre está situado en la cumbre de la jerarquía social, heciendo inútil e innecesaria de antemano cualquier cuestión sobre el origen de su fortuna, sobre su vida doméstica o sobre su relación con la sociedad. Pirro, Tamerlán, Ricardo II, el Cid, Otelo, Jerjes, Prometeo, Edipo, Sertorio, son reyes o príncipes, héroes guerreros o semidioses legendarios, figuras sagradas o forjadores de la historia. Su nombre indica su condición e implícitamente nos informa sobre los acontecimientos más notorios de su existencia; nos confía de golpe su nacionalidad, su situación familiar y, a veces, la pasión que les domina [...] Si se precisa su físico, es con una palabra muy general que señala edad, belle$\mathrm{za}$, rasgo dominante [...] Cada uno es libre de soñar el individuo que pueden ser, dentro de los límites impuestos por algunas afirmaciones que bastan para atestiguar su inserción en lo real7.

Dejando a un lado la potencialidad de los personajes históricos españoles que muestran un singular atractivo por su simple pertenencia al conjunto de los conquistadores, resulta
Robert Abirache, La crisis del personaje en el teatro moderno, Madrid, Publicaciones de la Asociación de Directores de Escena de España (Serie: Teoría y práctica del teatro, $\mathrm{n}^{\circ} 8$ ) 1994, p. 34.

Los araucanos como personajes literarios

MIGUEL ÁNGEL AULADELL PÉREZ 


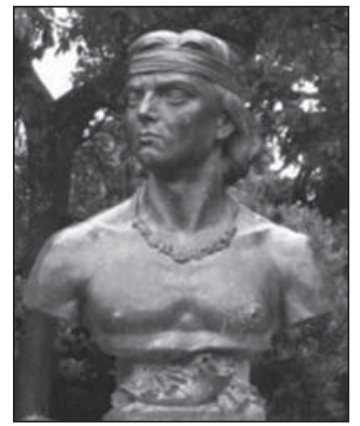

Busto de Lautaro en la plaza de Cañete, provincia de Arauco.

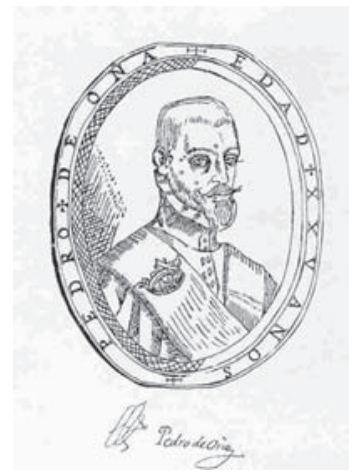

Pedro de Oña (grabado).

8

Ercilla, La Araucana, ed. cit., p. 39.

9

Darío Villanueva, «La recuperación del personaje», en Marina Mayoral (ed.), El personaje novelesco, Madrid, Cátedra/Ministerio de Cultura, 1990, p. 26.

\section{0}

Antonio Muñoz Molina, "La invención del personaje», en ibid., p. 89.

11

Ibid., pp. 89-90.

12

«El toqui Caupolicán y la prueba del tronco a la luzde un nuevo texto. Entre etnohistoria y literatura», Colonial Latin America Review, 15:1 (2006), pp. 3-28.

13

Ibid., p. 14.

14

Ibid., p. 18.

Los araucanos como personajes literarios

MIGUEL ÁNGEL AULADELL PÉREZ enormemente destacado el abanico de posibilidades retratísticas y figurales de los famosos rebeldes araucanos. En La Araucana, por ejemplo, según Isaías Lerner:

El heroísmo [...] continúa manteniendo las dimensiones que exige el imaginario épico y se reparte igualmente entre ambos campos, aunque algunos actos individuales permiten una caracterización multidimensional, como en el caso de Tucapel y Rengo, en los que la rivalidad proverbial servirá para dar extraordinario brillo y suspenso de corte ariostesco al Canto final de la Segunda parte. En la derrota, el valor araucano adquiere dimensiones hiperbólicas y la represión española multiplica desmesuradamente la crueldad8.

Asistimos aquí a una especie de impulso colectivo, o unánime en sagaz expresión de Romains, como el experimentado por Valle-Inclán cuando el narrador de personajes inconfundibles de sus primeras obras, experimenta ese impulso en la visita que en 1916 realiza al frente durante la Gran Guerra en Francia. Valle-Inclán, arquitecto de personajes muy caracterizados en la primera parte de su producción, transforma su patrón al componer su reportaje como corresponsal en $\mathrm{La}$ media noche. Visión estelar de un momento de guerra (1917), en donde se queja de que la humana limitación que impide estar a la vez en varios lugares hace prácticamente imposible el relato de un hecho tan radicalmente colectivo como es una guerra moderna. Se declara fracasado de antemano y apunta como paliativo el recoger las narraciones individuales de cada uno de los soldados supervivientes. Esos «cientos de miles de relatos, expresión de otras tantas visiones», se amalgamarán "para crear la visión colectiva, la visión de todo el pueblo que estuvo en la guerra y vio a la vez desde todos los parajes todos los sucesos» ${ }^{9}$. Esa misma actitud de don Ramón María pervive tanto en Tirano Banderas como en El Ruedo Ibérico. Pero en nuestro caso conservamos aún un protagonista individual en el que no advertimos la disgregación del héroe. Por el contrario, el relato que comienza Ercilla configura unos personajes que devienen en mitos al andarse el camino desde los hechos (Historia) hasta la palabra (Literatura). Y las primeras palabras son los propios nombres de los distintos caracteres. Antonio Muñoz Molina se muestra convencido de que la única cara de un personaje literario es su nombre ${ }^{10}$. En la literaturización de los hechos históricos que protagonizan Caupolicán y los otros héroes mapuches enfrentándose a los conquistadores españoles existe algo más permanente que la propia peripecia narrada, existen unos nombres concretos que van habitando las diversas obras en las que se da cobijo a la historia de los mapuches. Para calibrar en su justa medida el rendimiento que la creación de personajes ha de presentar de cara al lector, téngase en cuenta esta otra afirmación de Muñoz Molina cuando dice que:

Después de leer una novela lo primero que olvidamos es el argumento. Lo segundo -al menos en mi caso- es el estilo. Por lo que permanecen las novelas en nuestra memoria es por alguno de sus personajes. Nuestro oficio se parece al del rabino de Praga que hizo un Golem, una figura de barro a la que le infundió vida y movimiento trazando en su frente unas palabras mágicas ${ }^{11}$.

Caupolicán, elegido toqui por los araucanos para encabezar el levantamiento contra los españoles, nos ha quedado caracterizado casi mágicamente. Por una parte, un coloso de fuerza descomunal que es capaz de devolver la dignidad a su pueblo amenazado en su identidad. Por otra, un ejemplo de valor y de vigor al cumplimentar o completar el sacrificio que supone una prueba física tan penosa como cargar con un pesado tronco.

La simbología del personaje que instituye su naturaleza de héroe épico nacional nos remite a una especie de salvador, en definitiva un nuevo Cristo que puede concebirse como redentor. En un reciente y documentadísimo trabajo, Miguel Zugasti ${ }^{12}$ ha tratado de la presentación que las diversas versiones (tres autores del siglo XVI: Herrera, Vivar y Erci1la) nos han hecho de la hazaña del toqui con el madero como algo real. Efectivamente, Zugasti afirma que «el certamen del tronco fue real y, en su esencia, rigurosamente histórico, probablemente aplicación no ya tanto del ingenio ocasional de un anciano cuanto de una práctica habitual entre los aborígenes araucanos» ${ }^{13}$. Para sustentar su tesis con mayor apoyo esgrime un nuevo texto, el de las hazañas de Pedro Ordóñez de Ceballos contadas por Bartolomé Jiménez Patón. Zugasti lo presenta como un texto paralelo y anota las semejanzas y diferencias con el relato de Ercilla o el de Vivar. La coincidencia más destacable es «el inequívoco triunfo de los candidatos, que son aclamados por el resto; a saber: Caupolicán (o Teopolicán) para los araucanos y Capi (o Capite) para los taironas» ${ }^{14}$. Estos últimos habitaban una zona 
tan alejada de Chile como Urabá y Caribana (Caribe colombiano). Constata, pues, Zugasti que: «A la luz de este nuevo texto [...] gana entidad la idea de que, al menos entre los indios taironas y los araucanos (tan distantes unos de otros), existía el método del madero como proceso selectivo de un jefe o cacique guerrero» ${ }^{15}$. El hecho de que por tratarse de un autor culto, Jiménez Patón conociera la obra de Ercilla no resta, según Miguel Zugasti, credibilidad a su relato:

En conclusión, la relectura de este pasaje sobre los taironas refuerza la tesis de que la prueba del tronco descrita en La Araucana es auténtica; reflejo veraz, de tono etnográfico, de una práctica común entre los indios araucanos, taironas y quizás otros de quienes no han sobrevivido noticias (y, allende las fronteras americanas, de los turcos de Constantinopla, como bien lo testimonia Diego Galán). El que los antropólogos no hayan detectado su uso en las tribus o pueblos aborígenes en los tiempos modernos (siglos XIX-XXI), no invalida la vigencia de dicho procedimiento en el siglo XVI, tal y como lo atestiguan Vivar, Herrera, Ercilla y Ordóñez de Ceballos-Jiménez Patón ${ }^{16}$.

Aunque sólo sea desde una perspectiva antropológica, es curioso también el paralelismo que tiene en otros territorios americanos esa antigua tradición de los caciques mapuches de superar duras pruebas para «cargar» con el elevado cometido de acaudillar a su pueblo. Concretamente, en México existe una fiesta en honor de la Virgen de Guadalupe en la que se nos remite al período de la conquista por parte de Cortés que, por cierto, sale como figura en paso procesional junto a una mascarada en la que se dramatiza el enfrentamiento entre los indígenas y los españoles. S.M. Eisenstein en su filme iQué viva México! rodó toda una estremecedora secuencia, en la que se recogen dichos festejos y su culminación que sucede cuando todo el pueblo peregrina al templo que ocupa lo alto de una antigua pirámide azteca o tolteca. Van todos subiendo de rodillas dejando un pasillo por el que caminan unos penitentes, que como una especie de crucificados intentan reproducir los sufrimientos de Cristo y llevan atadas a los hombros unas cruces hechas con tallos rectos de cactus. Tardan varias horas en alcanzar la cima. A lo largo del camino, diversas mujeres les dan de beber y al fin, el director nos muestra un plano en el que se ve encima de la cúpula -a guisa de Calvario- a tres de estos esforzados disciplinantes. La iconografía de esta secuencia de la película de Eisenstein nos transmite muy plásticamente el fenomenal esfuerzo que realizaría Caupolicán alcanzando su propio calvario.

La condición que alcanza Caupolicán como personaje literario arrebatado a la historia, al igual que ocurre con los otros componentes del elenco que nutren las obras que recogen el asunto, es equiparable a la que nos presentan los personajes novelescos, los modernos héroes de la épica y también a la de las dramatis personae, puesto que no hay que olvidar que fue en el teatro donde la historia de los araucanos tuvo un mayor desarrollo.

Durante mucho tiempo se ha afrontado el estudio de los personajes con criterios tomados de

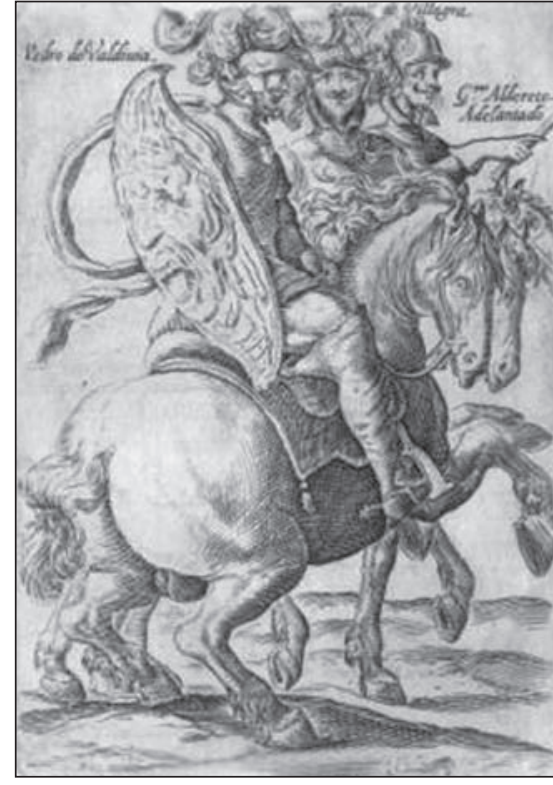

Valdivia, Villagrá y Alderete, según Ovalle. la psicología, la historia, la sociología o la filosofía. Don Quijote, la Celestina, Don Juan o Emma Bovary se han estudiado como casos psicológicos, símbolos de las posturas del hombre ante la vida o productos de unas circunstancias sociales determinadas. Más adelante se ha estudiado el personaje como un elemento más de la estructura literaria de la obra: como una función o un actante. Pero la pregunta sigue estando presente: ¿Cómo se construye un personaje? En el caso de un personaje que se basa en un referente histórico no una creación totalmente ficcional por parte del autor literario, pero sí que existe el empleo de unos recursos caracterizadores que son los propios de la construcción general del personaje. Si como pensaba Pirandello, el drama es la razón de ser del personaje, su función vital, necesaria para existir, en el caso de Caupolicán estaríamos principalmente ante un tipo de personaje-drama que como apuntaba Julián Marías, al tratar de Unamuno, consiste en ir siendo, es decir, en hacer consustancial la peripecia del personaje con el propio relato.

En Arauco domado, Lope de Vega nos presenta una especie de Laurencia (la protagonista de Fuente Ovejuna) en la figura de la araucana Fresia. Se trata de un personaje indomado. En Fresia, esposa de Caupolicán, Lope concentra los momentos de mejor poesía dramática. El personaje femenino se va transformando a medida que la acción pasa de la victoria de Caupolicán a la derrota, de la derrota a la tentación del compromiso, de la tentación del compromiso al vencimiento y a la destrucción. Es ese proceso el que transforma a Fresia
15
Id.
16
ld.

Los araucanos como personajes literarios

MIGUEL ÁNGEL AULADELL PÉREZ 


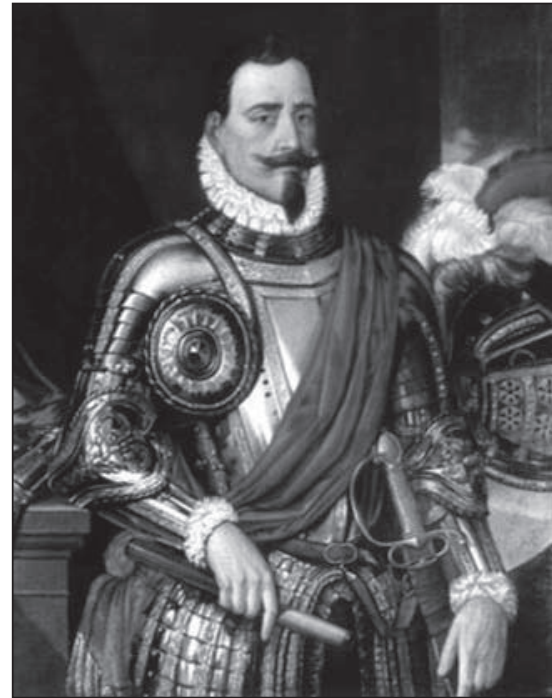

Pedro de Valdivia. en personaje portador o personaje símbolo del tema central del drama: la libertad. He aquí dos imágenes dramáticas de ese proceso de metamorfosis simbólica del personaje: En la Segunda Jornada, la noticia de la primera derrota de los araucanos la trae Engol, hijo (todavía niño) de Caupolicán y Fresia; y en la última, Caupolicán ha sido hecho prisionero y está atado a un palo. La escena final presenta dos apariencias. En la primera, Caupolicán, amarrado al madero, confiesa su conversión al cristianismo. En la segunda, una estatua de Felipe II, a la que rinden homenaje los que están encima del tablado, ocupa el lugar de Caupolicán. Entre ellas resaltan las voces de Fresia y de Engol jurando venganza. Es este anuncio de venganza, y no la apoteosis de la efigie de Felipe II, la que domina y cierra dramáticamente la tragedia del indio vencido. Este mismo indio vencido aparecerá en La Araucana 'auto' como figura de Cristo redentor. Afirma Francisco Ruiz Ramón que si a D. Marcelino Menéndez y Pelayo tal identificación le levantaba ampollas, a los lectores y espectadores actuales puede parecerles significativa y fascinante la asociación del personaje Caupolicán con la figura de Cristo.

Otro ejemplo significativo en la adaptación de la materia histórica a la literatura dramática es Los españoles en Chile, la obra más tardía sobre las guerras de Arauco. Patricio Lerzundi ha subrayado el hecho de que se hace prácticamente imposible determinar de dónde obtuvo el autor, Francisco González de Bustos, el marco histórico para organizar la trama de su comedia. En 1665, fecha de edición de la pieza, había pasado más de un siglo con relación a los acontecimientos históricos que conforman el asunto. Se constata un error cronológico, puesto que se pone a don Diego de Almagro, fallecido en 1538, junto a don García Hurtado de Mendoza, llegado a Chile en 1557. Se deduce que el autor aprovechó crónicas, historias, obras dramáticas, todo lo que sobre el tema de Arauco le pudo servir de alguna manera. Diego de Almagro, el hombre histórico de carne y hueso le sirve en el sentido de que efectivamente fue el primer conquistador de Chile; por otra parte, desde el punto de vista de protagonista literario, le da la pauta para usarlo como símbolo del con- quistador de mujeres y puede por lo mismo llegar a ser un «lindo don Diego». Aun con todas estas limitaciones, es posible encontrar ciertos ecos del Aranco domado de Lope, de Algunas hazañas de las muchas de Don García Hurtado de Mendoza, Marqués de Cañete, obra dramática de Luis de Belmonte Bermúdez y otros, y por último de El Gobernador prudente, de Gaspar de Ávila.

La historia de Caupolicán sigue viva hoy. No sólo contamos con los monumentos literarios que le han convertido en un personaje literario de gran recorrido cronológico y genérico, sino que existe por toda la geografía de la Araucania y de Chile en general una continuada representación iconográfica del héroe, así como de otros compañeros de rebeldía, en especial Lautaro. Ellos y los conquistadores españoles con los que lucharon componen conjuntos escultóricos y recreaciones plásticas que contribuyen a mantener viva el alma del pueblo mapuche. Aún hoy parece que se re-escriben nuestros personajes. Una noticia publicada en prensa hace pocos meses ( $E l$ Mundo, domingo, 7 de enero de 2007) nos ofrecía el siguiente titular: «El español que 'robó el alma' a un mapuche. Los indígenas chilenos culpan a un turista por el suicidio de un miembro de su comunidad». La crónica del corresponsal comenzaba así: «El médico forense determinó que Germán Catrilaf se quitó la vida, posiblemente a causa de una depresión. Pero los indígenas mapuches del sur de Chile tienen la certeza de que se ahorcó porque un turista español le robó el alma. 'Los huincas (españoles, o por extensión, hombres blancos) no se conforman con habernos invadido y despojado de nuestras tierras, aguas y bosques. Ahora quieren quitarnos la vida', sentenció Lautaro Catrilaf, hermano del difunto». La única guinda que añadiría a lo dicho es renombrar al fallecido: Caupolicán debiera ser para redondear la historia.

Falta una novela histórica, género tan en boga actualmente, o una adaptación cinematográfica de fuste para nuestro asunto, motivo y mito. Caupolicán y los otros personajes araucanos y españoles pueden hoy interesar a un público amplio que anda rendido ante los superhéroes del cómic o del cine de costosos efectos especiales. Habría que dar la necesaria réplica a la reciente Apocalypto, última cinta de Mel Gibson, polémica como casi todas las suyas, que recrea la decadencia del imperio maya y sus sangrientos rituales y que está rodada en yucateco. 